\title{
A Case of Pleomorphic Adenoma with Formation of a Large Cyst: Histomorphometric analysis of tumor cells
}

\author{
Ken Onodera, Hu Ji-Min, Yukiko Yamamura, Masato Yamaguchi*, Ryo Ichinohasama and Kiyoshi Ooya \\ Department of Oral Pathology, Tohoku University School of Dentistry, Sendai, Japan \\ *Department of Surgery, NTT Tohoku Hospital, Sendai, Japan
}

\begin{abstract}
Onodera K, Hu J-M, Yamamura Y, Yamaguchi M, Ichinohasama $R$ and Ooya K. A case of pleomorphic adenoma with formation of a large cyst: Histomorphometric analysis of tumor cells. Oral Med Pathol 1998; 3: 89 92 ISSN 1342-0984.
\end{abstract}

\begin{abstract}
We describe a case of pleomorphic adenoma associated with the formation of a large oval cyst in the right parotid gland in a 54-year-old Japanese man. The proliferative activity of the tumor cells was evaluated by counting the number of argyrophilic nucleolar organizer regions (AgNORs). The tumor, measuring $17 \times 12 \times 12 \mathrm{~mm}$, was a clearly demarcated mass with an almost cystic appearance. It contained whitish cheese-like material. Histologically, the cyst cavity was filled with keratin and was lined by keratinizing squamous tumor cells. Flattened tumor cells were found in the hyalinized stroma. Adjacent islands of squamous metaplastic tumor cells and glandular tumor cells were present. The mean number of AgNORs per nucleus of tumor cells in the glandular portion, mildly keratinizing lining, highly keratinizing basal lining, highly keratinizing superficial lining, and flattened portion was $2.2 \pm 0.9,1.7 \pm 1.1,1.6 \pm 1.2,1.2 \pm 0.9$, and $1.3 \pm 0.8$, respectively. Our results suggest that in some pleomorphic adenomas, small squamous metaplastic tumor islands might aggregate and lead to the formation of a large cyst in which the keratinizing tumor cells of the lining have higher proliferative activity than the flattened tumor cells in the hyalinized stroma.
\end{abstract}

Key words: Pleomorphic adenoma, Cyst, Lining epithelium, AgNORs

Correspondence: Ken Onodera, Department of Oral Pathology, Tohoku University School of Dentistry, 4-1 Seiryo-machi, Aoba, Sendai, Miyagi 980-8575, Japan

\section{Introduction}

Pleomorphic adenoma is the most common benign tumor arising in both the major and minor salivary glands. It is often associated with the formation of a small cyst (1). The formation of a large cyst is rare in pleomorphic adenoma (2-5), and moreover a true cyst lined with tumor cells rarely occurs (4-8). Although several studies have compared the proliferative activity of cells in pleomorphic adenoma with that of cells in malignant salivary gland tumors $(9,10)$, the relation between the proliferative activity of tumor cells and cyst formation has received little attention. We studied an unusual case of pleomorphic adenoma associated with a large cyst lined with keratinizing squamous tumor cells and evaluated the proliferative activity of the tumor cells to investigate the relation to cyst formation.

\section{Case report}

A 54-year-old man was referred to NTT Tohoku Hospital (Sendai, Japan) in February 1997 because of a painful swelling in the right parotid region. Although the patient had been aware of this mass for 20 years, he ignored it because it was small and caused no pain or facial palsy. The lesion grew rapidly and caused minor pain during the month before presentation. On admission, a large, elastic soft mass was palpated in the right parotid region. There was no tenderness. The clinical diagnosis was a benign parotid tumor. Extirpation of the tumor was performed. During the operation, the tumor was confirmed in the superficial lobe of the right parotid gland. It was well enclosed by a fibrous capsule. There was no evidence of invasion. The surgically removed specimen, measuring $17 \times 12 \times 12 \mathrm{~mm}$, was a clearly demarcated mass that closely resembled a cyst. It contained whitish cheese-like material. At the time of this writing, more than 18 months after the operation, the patient is well, with no evidence of recurrence.

\section{Materials and Methods}

The surgical specimen was immediately fixed in $10 \%$ buffered formaldehyde and embedded in paraffin. Sections were cut at a thickness of $3 \mu \mathrm{m}$ and mounted on 
glass slides. Hematoxylin and eosin staining, and AgNOR staining (11) were performed. For AgNOR staining, paraffin sections were dewaxed in xylene and then hydrated through a graded series of ethanol to water. The AgNOR staining solution was a $2 \%$ solution of gelatin in $1 \%$ formic acid. One volume of this solution was combined with two volumes of $50 \%$ silver nitrate solution. The prepared solution was poured over the tissue sections and allowed to stand 30 minutes in a darkened room. The sections were then washed with deionized water, dehydrated to xylene, and mounted.

\section{Pathological and AgNOR findings}

Microscopically, a well-circumscribed tumor mass was present with a large cystic cavity containing substan-

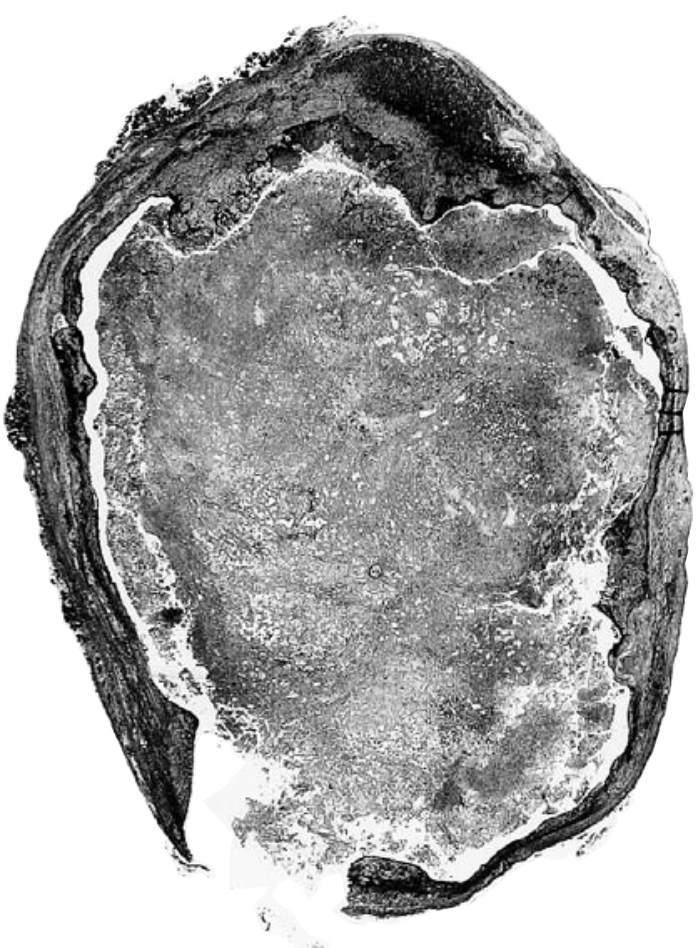

Fig. 1: A well-circumscribed tumor resembling a cyst containing keratin. Normal parotid glands around the capsule $(\mathrm{HE}, \times 5)$. tial amounts of keratin, cell debris, and necrotic tumor cells. The tumor mass was nearly composed of the cystic wall and lumen, and the solid part of the tumor was partly shown in the wall. Inflammatory cell infiltration was mild. Normal parotid glands were seen adjacent to the capsule (Fig.1). Solid, tubular, or glandular epithelial parenchyma was focally located in the cystic wall (Fig.2a). The stroma consisted of the fibrous connective tissue with the hyalinized change. The tumor cells lining the cyst consisted of mildly keratinizing (Fig.3), highly keratinizing (Fig.4), and flattened components (Fig.5). Many strands of tumor cells were observed in the underlying connective tissue of the cystic wall, and connected with the lining tumor cells. The inner surface of the cyst was comprised of $59 \%$ mildly keratinizing components, $25 \%$ highly keratinizing components, and $16 \%$ flattened components. Most of the inner surface $(59 \%+25 \%=84 \%)$ of the cyst was lined by keratinizing squamous tumor cells. In the mildly keratinizing area, degenerative and necrotic tumor cells were present on the surface. A histological shift from solid tumor cells to squamous tumor cells was seen along with several small islands of squamous metaplastic cells (Fig.3). In the highly keratinizing area, a thick lining of tumor cells was present with superficial massive keratinized and degenerated cells (Fig.4). In the flattened cell area, one or two layers of tumor cells were seen, associated with a markedly hyalinized stroma (Fig.5). Mitoses were exceptional in tumor cells. No chondroid or osteoid tissue was present.

On light microscopical examination, AgNORs of tumor cells were clearly visualized as dark brown dots within orange-stained nuclei. The mean number of AgNORs per nucleus (AgNOR number) of the tumor cells in this area was $2.3 \pm 0.9$ (Fig. 2-b). The mean AgNOR number of tumor cells in the glandular portion, mildly keratinizing lining, highly keratinizing basal lining, highly keratinizing superficial lining, and flattened portion was $2.2 \pm 0.9,1.7 \pm 1.1,1.6 \pm 1.2,1.2 \pm 0.9$, and $1.3 \pm 0.8$, respectively (Fig.6). The mean AgNOR number was significantly less in tumor cells of the highly keratinizing

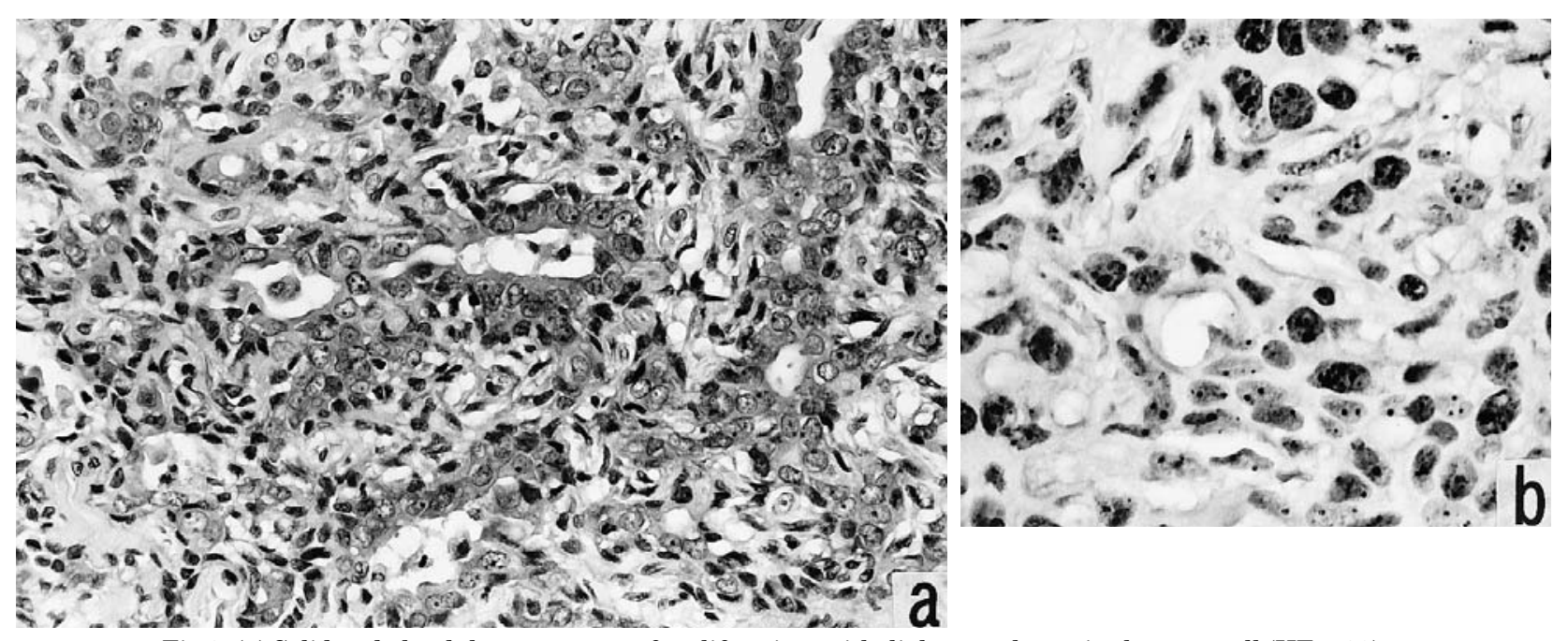

Fig.2: (a) Solid and glandular structures of proliferating epithelial parenchyma in the cyst wall $(\mathrm{HE}, \times 90)$.

(b) Tumor cell nuclei contain silver-stained AgNOR particles (AgNORs staining, ×200). 


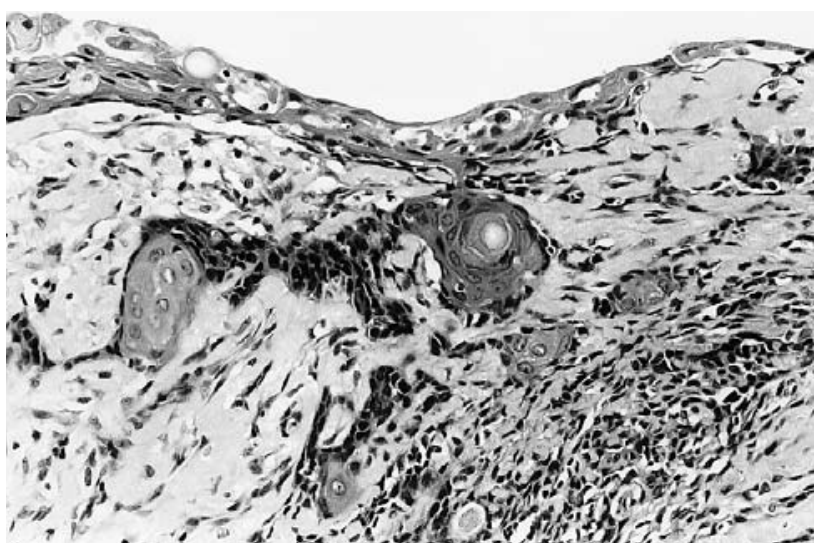

Fig.3: Mildly keratinizing squamous tumor cells with several small squamous metaplastic islands $(\mathrm{HE}, \times 90)$.

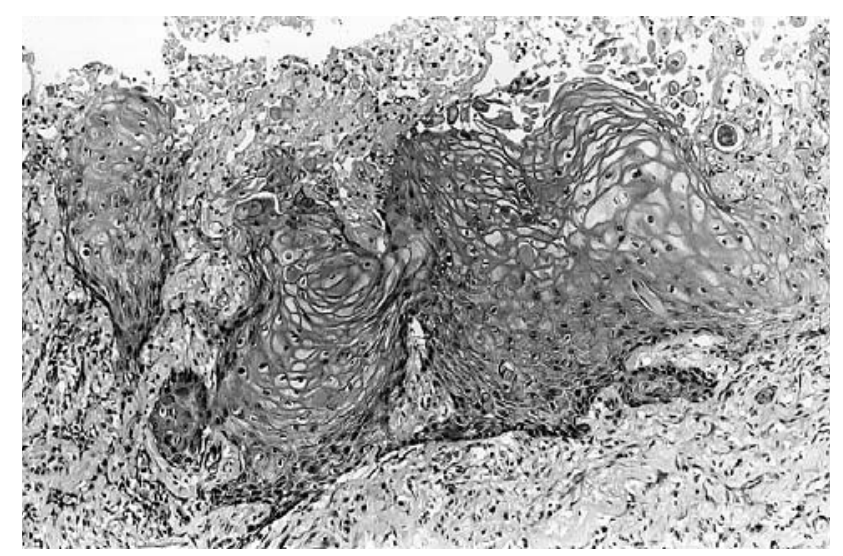

Fig.4: Highly keratinizing and thick squamous tumor cells with superficial massive keratinized and degenerative cells $(\mathrm{HE}, \times 80)$.

superficial lining and the flattened portion than in the glandular portion $(\mathrm{p}<0.001)$.

\section{Discussion}

Pieterse and Seymoour (7) reported cyst formation in $2(2.3 \%)$ of 87 pleomorphic adenomas of the parotid gland. Macroscopically identifiable large cysts are rare in pleomorphic adenoma. Abiko et al. (8) proposed four mechanisms leading to the formation of large cysts in pleomorphic adenoma: 1) focal necrosis caused by tumor cells with squamous metaplasia; 2) enlargement of ductlike structures due to excessive secretion of fluid by tumor cells or salivary gland tissue; 3 ) hemorrhage; and 4) in malignant tumors, necrosis. In our case, the cyst wall was lined by stratified squamous epithelium, and there was no evidence of hemorrhage or mucus secretion. Therefore, the cyst in our patient most likely resulted from the first mechanism. The presence of a stratified squamous epithelium lining was similarly reported by Devgan and Devgan (4), who referred to this phenomenon as "epidermal inclusion cyst in pleomorphic adenoma". Furthermore, Sasaki et al. (5) observed a ciliated epithelium lining in cystic pleomorphic adenoma. This ciliated epithelium lining might have resulted from metaplasia of tumor cells.

The epithelial lining of the cyst in our case showed

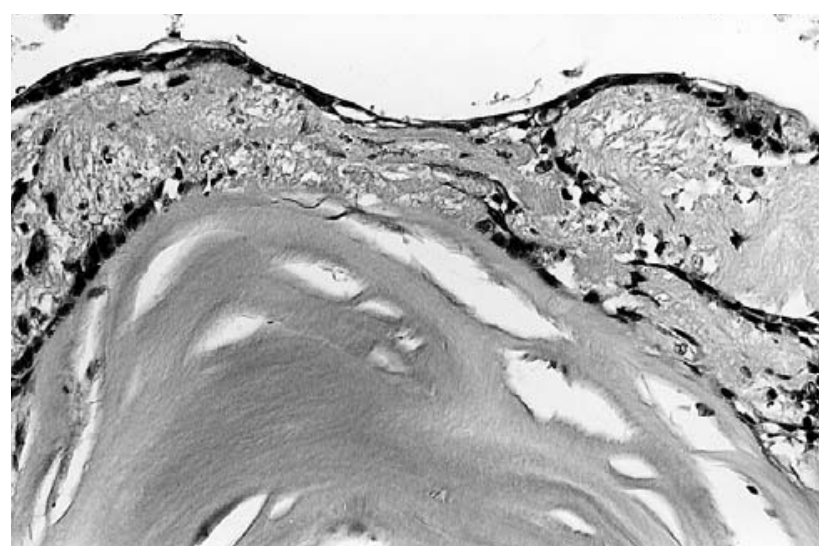

Fig.5: One or two flattened layers of tumor cells with marked hyalinized stroma $(\mathrm{HE}, \times 100)$.

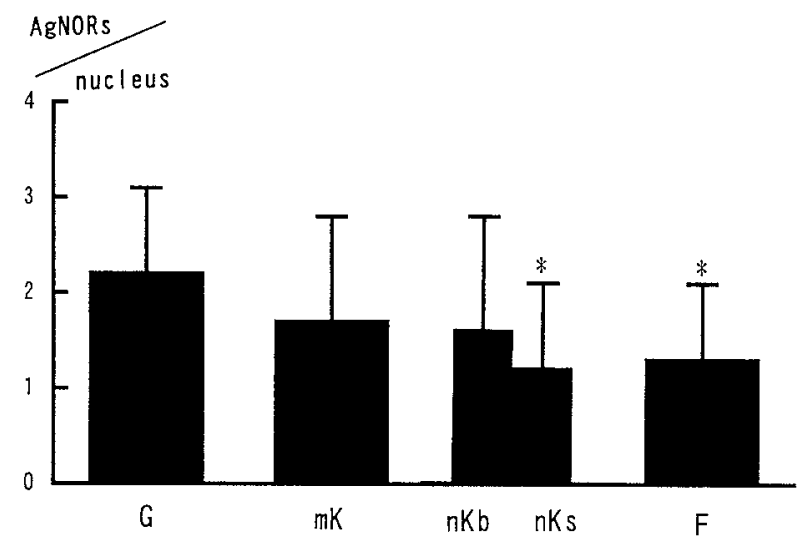

Fig.6: Mean AgNOR number according to site. G : glandular, $\mathrm{mK}$ : mildly keratinizing lining, $\mathrm{hKb}$ : highly keratinizing basal lining, hKs : highly keratinizing superficial lining, and $\mathrm{F}$ : flattened tumor cells $(*, \mathrm{p}<0.001)$.

three keratinization patterns: mildly keratinizing squamous tumor cells, highly keratinizing squamous tumor cells, and flattened tumor cells. The proportions of the different keratinization patterns of lining tumor cells might reflect the clinical course of our patient, who showed a rapid increase in tumor size during a period of 1 month after slow growth over a period of 20 years. Keratinizing tumor cells, lining $84 \%$ of the entire inner surface of the cyst, might be intimately related to the rapid increase in tumor size. Since our case showed several squamous metaplastic islands closely associated with the lining cells, the large cyst could have resulted from the merging of these islands in association with the accumulation of keratin and degenerative tumor cells. Although Dardick et al. (12) reported that various degrees of squamous metaplasia occur in $25 \%$ of pleomorphic adenomas, it is quite difficult to explain conditions conducive to the development of large cysts in this neoplasm. On the other hand, the possibility remains that the large cyst could have resulted from the central degeneration or necrosis of the tumor. But such a cyst might have no lining cells or it might be exposed to tumor cells.

The contents of the cystic cavity were apparently produced by the keratinizing lining epithelium. In our AgNOR examinations, the mean AgNOR numbers in tumor cells of the highly keratinizing superficial lining 
and flattened portion were significantly less than that in the glandular portion. These findings indicate that the proliferative activities of cells lining the cyst differ according to site, and that flattened tumor cells show degenerative changes with low proliferative activity. Perhaps cells lining highly keratinizing superficial regions produce large amounts of keratin.

\section{References}

1. Eneroth CM. Salivary gland tumors in the parotid gland, submandibular gland, and the palate region. Cancer 1971; 27: 1415-8

2. Moore HD. Parotid cysts. Br Med J 1950; 18: 649.

3. Frylinck JR. An unusual tumour. S Afr Med $J$ 1956; 30: 479.

4. Devgan $M$ and Devgan BK. Epidermal inclusion cyst in pleomorphic adenoma (mixed parotid tumor). Ear Nose Throat J 1977; 56: 75-7.

5. Sasaki A, Yokoyama S, Daa T, et al. A ciliated cyst as a component of pleomorphic adenoma of the parotid gland. $J$ Oral Pathol Med 1997; 26: 385-7.

6. Richardson GS, Clairmont AA and Erickson ER. Cystic lesions of the parotid gland. Plast Reconstr Surg 1978; 61: 364-70.
7. Pieterse AS and Seymour AE. Parotid cysts. An analysis of 16 cases and suggested classification. Pathology 1981; 13: 225-34.

8. Abiko Y, Kaku T, Shimono M, et al. Large cyst formation in pleomorphic adenoma. Bull Tokyo Dent Coll 1993; 34: 9-14.

9. Ishii K and Nakajima T. Evaluation of malignant grade of salivary gland tumors: studies by cytofluorometric nuclear DNA analysis, histochemistry for nucleolar organizer regions and immunohistochemistry for p 53. Pathol Int 1994; 44: 287 $-96$.

10. Martin AR, Mantravadi J, Kotylo PK, et al. Proliferative activity and aneuploidy in pleomorphic adenomas of the salivary glands. Arch Pathol Lab Med 1994; 118: 252-9.

11. Ploton D, Menager M, Jeannesson P, et al. Improvement in the staining and in the visualization of the argyrophilic proteins of the nucleolar organizer region at the optical level. Histochem $J$ 1986; 18: 5-14.

12. Dardick I, Jeans MT, Sinnott NM, et al. Salivary gland components involved in the formation of squamous metaplasia. Am J Pathol 1985; 119: 33-43.

(Accepted for publication October 26, 1998) 